ARTIGO ORIGINAL ORIGINAL ARTICLE

\title{
The use of micro-costing in an economic analysis of allogeneic HSCT in Brazil
}

\author{
O uso do microcusteio na análise econômica \\ do TCTH alogênico no Brasil
}

Dora Fraga Vargas', Caroline Nespolo de David', Jaqueline Driemeyer Correia Horvath', Tatiana Schnorr Silva', Mariana Pinto Pereira', Lisandra Della Costa Rigoni1,2,3, Ivaine Tais Sauthier Sartor', Gabriela Oliveira Zavaglia', Luciane Beatriz Kern', Thainá Dias Luft', Fernanda Lutz Tolves' ${ }^{1}$, Fernanda Fetter Scherer 1,3,4, Jaina da Costa Pereira1, Fabiano Barrionuevo', Ana Paula Beck da Silva Etges ${ }^{5}$, Bruna Stella Zanotto ${ }^{5}$, Liane Esteves Daudt 3,4,6, Luciane Nascimento Cruz ${ }^{1,5}$, Carisi Anne Polanczykk, , Claudia Caceres Astigarraga 2,3,6

DOI: 10.21115/JBES.v13.n2.p166-74

Palavras-chave: microcusteio, TDABC, análise de custos, transplante de células-tronco hematopoéticas

\section{RESUMO}

Objetivo: O objetivo deste estudo foi estimar os custos do tratamento do transplante de células-tronco hematopoéticas (TCTH) em um centro de referência no Brasil. Métodos: A população do estudo foi composta por pacientes provenientes da lista de TCTH do Sistema Único de Saúde submetidos ao TCTH em um hospital do sul do Brasil, entre 2016 e 2019. A avaliação de custos foi realizada por meio de um estudo de microcusteio, baseado no Time-Driven Activity-based Costing (TDABC) adaptado para estudos econômicos em saúde e incluiu as seguintes etapas: definição da questão de pesquisa, coleta de dados estruturada e análise estatística dos resultados. Resultados: 0 custo total do TCTH foi de \$155.110 (\$92.794 - \$249.146 USD). OTCTH de doador não aparentado compatível foi mais caro do que o TCTH de doador aparentado compatível. Os principais fatores de custo envolvem complicações pós-transplante, principalmente a ocorrência de infecções. Em relação à composição dos custos, exames e procedimentos representam o maior custo em TCTH (45\%). Conclusão: Essas estimativas podem ser aplicáveis a novas avaliações de custo-efetividade do TCTH e ajudar os gestores na tomada de decisão em saúde, especialmente em países de média renda.

\section{Keywords:}

micro-costing, TDABC, cost analysis, hematopoietic stem cell transplantation

\begin{abstract}
Objective: The objective of this study was to estimate treatment costs of Hematopoietic stem cell transplantation (HSCT) at a reference center in Brazil. Methods: The study population consisted of patients from the Unified Health System HSCT who underwent HSCT in southern Brazil between 2016 and 2019. Costs were measured using a micro-costing approach, based on Time-Driven Activity-based Costing (TDABC) adapted for economic studies in health and included the following steps: definition of the research question, structured data collection, and statistical analysis of results. Results: The total cost of HSCT was $\$ 155,110$ (\$92,794 - \$249,146 USD). Matched unrelated donor HSCT was more expensive than matched related donor HSCT. The major cost factors involve post-transplant complications, mainly the occurrence of infections. Concerning cost composition, exams and procedures represent the largest expense in HSCT (45\%). Conclusion: These estimates could be applicable to further evaluations for HSCT cost-effectiveness and help healthcare decision-makers in middle-income countries.
\end{abstract}

\footnotetext{
Received on: 06/25/21. Approved for publication on: 07/10/2021

1. Social Responsibility PROADI-SUS, Hospital Moinhos de Vento, Porto Alegre, RS, Brazil.

2. Oncology Service, Hospital Moinhos de Vento, Porto Alegre, RS, Brazil.

3. Hematology Service, Hospital de Clínicas de Porto Alegre, Porto Alegre, RS, Brazil.

4. Pediatric Service, Hospital Moinhos de Vento, Porto Alegre, RS, Brazil.

5. National Health Technology Assessment Institute, CNPq, Porto Alegre, RS, Brazil.

6. School of Medicine, Universidade Federal do Rio Grande do Sul, Porto Alegre, RS, Brazil.

Study institution: Hospital Moinhos de Vento

Funding: The data were obtained in partnership with the General Coordination Office to the National Transplant System-Brazilian Ministry of Health (CGSNT-MS) through the Institutional Development Support Program of the Brazilian Unified Health System (PROADI-SUS)

Congresses where the study was presented: ISPOR 2020 - Orlando.

Conflict of Interest Disclosures: None reported.

Corresponding author: Dora Fraga Vargas. Rua Ramiro Barcelos, 6030/1015. Phone: +55 (51) 35378573. Email: dorafv@gmail.com
} 


\section{Introduction}

Health system costs have been rising worldwide (Kaplan \& Porter, 2011; Porter \& Lee, 2013), which is at least partially due to the increasing complexity of some medical treatments. A premise of the Brazilian Unified Health System (Sistema Único de Saúde - SUS) is the integrality and equality of health care at all complexity levels (BRASIL, 1990). In this context, economic evaluation studies are essential for decision-making about prioritizing and planning health interventions and programs (Clarke-Deelder et al., 2019). In addition to macroeconomics, economic evaluation studies can also support local decisions in health organizations, allowing greater efficiency in services provided and improving the results (Donovan et al., 2014; Porter, 2010).

Little evidence is available about treatment costs for patients who require hematopoietic stem cell transplantation (HSCT), especially in developing countries (Rivera-Franco et al., 2017). HSCT is a potentially curative treatment, highly complex and costly, indicated for some malignant and nonmalignant hematologic diseases, genetic and immunodeficiency disorders, although it involves many early and late complications ( Ashfaq et al., 2010; Preussler et al., 2012; Wingard et al., 2011).

Determining the HSCT cost depends mainly on the chosen cost estimator since it differs in inference quality. Thus, the analysis method can influence the study results and subsequent economic analyses based on that information (Clarke-Deelder et al., 2019).

Micro-costing is the more accurate cost estimation method for evaluating health interventions (Xu et al., 2014), contributing to management (Etges et al., 2020). Time-driven activity-based costing (TDABC) aims to measure resources cost consumed by each patient. In addition to being more precise, it requires fewer resources to accomplish its task since it is based on only two parameters - activity and time (Kaplan \& Anderson, 2004). TDABC can more accurately determine the cost of healthcare and, thus, assist in controlling such costs, generating value for healthcare (Keel et al., 2017).

Studies assessing HSCT cost in low and middle-income countries are incipient. The few published have significant limitations, such as only evaluating the admission phase cost (Leelahavarong et al., 2010; Razgallah Khrouf et al., 2017) or the use of simple cost analysis (Jaime-Pérez et al., 2015). This study aimed to present a micro-costing assessment of HSCT in Brazil using the TDABC method, describing the main costs in each phase of HSCT and some clinical features that may be involved in these costs.

\section{Methods}

This is a prospective, longitudinal follow-up of patients who underwent HSCT between 2016 and 2019 in a hospital in southern Brazil to assess the clinical and economic aspects.
The sample consisted of 27 patients on the list for HSCT at a public institution treated at Hospital Moinhos de Vento, a private philanthropic hospital, through the Institutional Development Support Program of the Brazilian Unified Health System. During the study, patients eligible for allogeneic HSCT were followed in three phases: (1) the pre-HSCT phase - examinations and consultations with the multidisciplinary team to assess whether the patient can undergo the transplant; (2) the admission phase - between transplant and hospital discharge; (3) the immediate post-HSCT phase - between discharge and 100 days after transplant $(D+100)$. For patients who required readmission close to $D+100$, the follow-up was extended until hospital discharge. Donor expenditures were considered in the pre-HSCT phase (tests and consultations to assess health status and compatibility) and the admission phase (considering all costs involved with collecting stem cells, drugs, materials, human resources, and physical structure).

The cost assessment was based on TDABC adapted for economic studies in healthcare. It included the following steps: defining the research question, structured data collection, and statistical analysis of results (Etges et al., 2019). The care pathway for each phase of HSCT treatment, which identifies the main activities the patient undergoes, and all resources and physical structures involved, was mapped by a multidisciplinary team consisting of health technology assessment researchers and a technical staff specialized in HSCT. A starting point and an end-point for follow-up were defined for each patient (Etges et al., 2019) (Figure 1). The first patients (P1 to P12) underwent pre- and post-HSCT at another institution, performing only the admission phase at our center, which caused a difference in the sample size between phases. Data was collected through interviews with healthcare workers, time analysis, and from electronic medical records.

Data on fixed depreciation costs, energy, supporting materials, taxes, and system licenses were collected for estimating the total hospital structural costs; such data were collected at the cost centers of each department identified in the care pathway. In addition, the monthly service capacity of each department was calculated based on the number of beds and opening hours or the availability of teams essential to the activities. The mean base salary plus professional and institutional charges were used for estimating the total cost of healthcare worker wages. Time analysis and interviews with the professionals involved in the care of included patients were used to estimate the time required for each phase of the mapped care pathway.

The unit cost rate (Karabatsou et al., 2016; Leelahavarong et al., 2010; Nunes et al., 2010), the cost estimate of each resource divided by the estimated time capacity of each resource, was calculated using cost and capacity information according to resources. Regarding the physicians and dentists, it should be noted that they are considered self-employed; thus, the 
total cost per fee was used, and a unit cost rate could not be calculated. Monetary appreciation was based on 2019 prices in Brazil. Costs are presented in United States Dollars (USD), considering a conversion rate of $1 \mathrm{BRL}=0.25$ USD according to Central Baxnk of Brazil rates on 12/31/2019.

Activities of each phase of HSCT were identified by electronic medical record consultation, and all resources consumed were extracted and described. To assess the individual cost per patient, the time each patient used in each hospital department and the professional resources they required were multiplied by their unit cost rate. The costs of drugs and materials were added to this, considering the hospital's acquisition costs (excluding the institutional profit margin). For exams and other procedures (such as interventions in dermatology, urology, otorhinolaryngology, surgery and anesthesiology), the unit costs incurred by the hospital were considered.

Two known pre-transplant risk scores developed to estimate the mortality risk according to pre-HSCT clinical characteristics were calculated for each patient (Au et al., 2015; Gratwohl et al., 2009). The Pretransplant Assessment of Mortality (PAM) score includes patient age ( $<65$ or $>65$ years), donor type, disease risk, forced respiratory volume and patient/ donor cytomegalovirus serology (AU et al., 2015). The EBMT risk score includes patient age ( $<20,20-40$ and $>20$ years), disease stage, the time between diagnosis and HSCT $(<12$ or $>12$ months), donor type (related or unrelated), and donor-recipient gender combination (female donor to a male recipient or other combinations (Gratwohl, 2012).

The data were compiled in an Excel ${ }^{\circ}$ spreadsheet. The results are mean and standard deviation, median and interquartile range (IQR) or minimum and maximum, or absolute number and percentage (\%). The total cost of the care pathway was calculated for each patient and the entire sample of patients. The patient's global cost was estimated from the sum of medians of each phase. The cost information was presented considering the care pathway phases: pre-transplant, admission, and post-transplant. The risk score, the transplant type, the identification of infections, and the length of time waiting for the transplant were used as drivers for the cost analysis.

We used SPSS software, version 22, for statistical analyses. A univariate analysis was conducted to identify if the cost was associated with survival. For survival analysis, patients were categorized into low and high cost using the median as a cutoff point. Survival was estimated by the Kaplan-Meier method and compared with the log-rank test and Tarone-Ware test. The variables were compared with nonparametric tests, and the chi-square test analyzed differences between proportions. Time on the waiting list for HSCT (counted from finding a compatible donor to the transplant procedure) was categorized into $<200$ days or $\geq 200$ days. This study was approved by the Institutional Review Board of the involved institutions (IRB No 63004716.6.1001.5330 and 02898218.0.3001.5327).

\section{Results}

\section{Characterization of patients and transplants}

Twenty-seven patients were included, and it was possible to perform the data collection for 15, 26, and 7 patients in the pre-HSCT phase, the admission phase, and the immediate post-HSCT phase, respectively. Certain clinical complications during HSCT caused a reduction in the number of patients between the phases. Some of these complications are described hereafter: a) P20, for example, follow-up was interrupted in the pre-transplant phase due to the underlying disease relapse, making transplantation impossible at that time; the patient then died due to disease progression without having undergone HSCT; b) P1 to P12 did not undergo pre- or post-HSCT assessment at our institution and were admitted only for the HSCT procedure; c) P18 and $\mathrm{P} 23$, had a prolonged period of admission (exceeding $D+100)$; d) Other patients died during the admission phase (P14, P15, P16, P19, and P22), which made a post-HSCT micro-costing evaluation unfeasible. Figure 1 shows the follow-up time for micro-cost data collection for each patient at each phase of HSCT treatment. The mean follow-up time was 132.6 ( \pm 44.72) days.

Of the included patients, 19 were men and 8 were women, $85.2 \%(n=23)$ were adults ( $\geq 18$ years old), two were adolescents ( $P 1$ and $P 7$ were 17 years old) and two were children (P23 and P25 were 4 and 11 years old, respectively). Most cases were malignant diseases such as leukemia (acute and chronic). There was one case of myelodysplastic syndrome; only one case of non-malignant disease (aplasia) was included in this sample. The most frequent type of transplant was human leukocyte antigen (HLA) identical sibling donors/ matched related donor (MRD) ( $n=14,48.2 \%)$, followed by HLA-haploidentical ( $n=$ 7, 33.3\%) and matched unrelated donor (MUD) ( $n=5,18.5 \%)$. The most widely used hematopoietic stem cell source was peripheral blood (70.4\%); bone marrow was used in only eight patients.

This sample had a pre-transplant risk score intermediate and high by the EBMT score (65.4\% and 26,9\%, respectively) and PAM score ( $42.3 \%$ and 15,4 , respectively). Seven patients (26.9\%) were classified as low risk (P1, P2, P3, P17, P19, P25, P26) by PAM score, while only two patients (7.7\%) were classified as low risk by EBMT score (P1 e P25).

\section{Pre-HSCT costs}

The median cost was 742 USD (IQR 25,75: 429 - 1,497 USD). The highest cost was related to medical exams and dental procedures, with the latter accounting for $23 \%$ of the total cost. Medical materials and medications represented an almost negligible part of the cost in this phase (0.47\%). The median cost of donor evaluation in the pre-transplant phase was 282 USD (IQR 25,75: 230 - 824 USD), and most of the cost was laboratory examinations. 


\section{Admission phase costs}

The median cost of the admission phase was 56,893 USD (IQR 25,75: 32,165 - 193,714 USD). This phase was subdivided into patient admission, conditioning, transplant day, aplasia period (from the first day after graft infusion until bone marrow engraftment), observation, preparation for discharge, and discharge. Admission costs varied considerably between patients from 34,084 to 461,873 USD, as did admission phase time (from 34 to 141 days) (Figure 2).

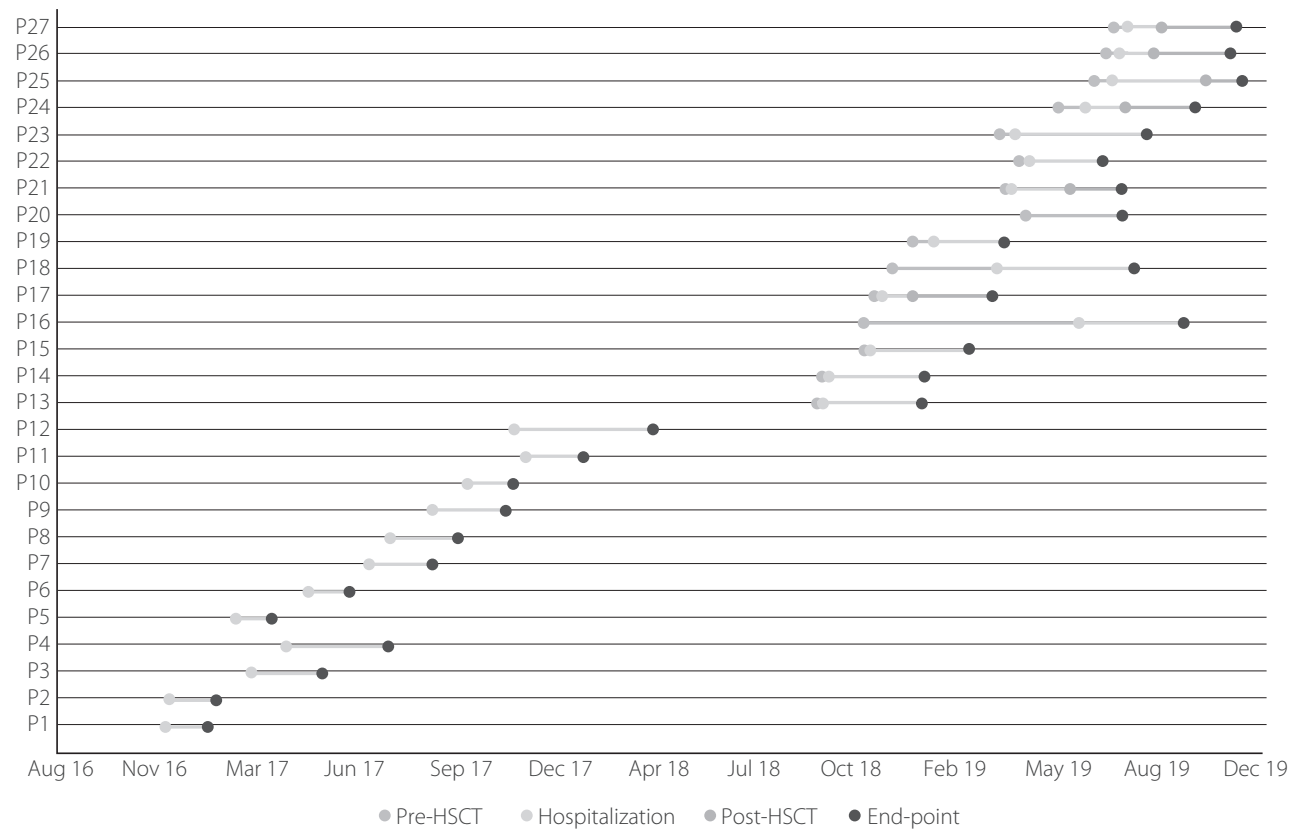

HSCT: hematopoietic stem cell transplantation. Data presented as date.

Figure 1. Patient monitoring during each phase of HSCT treatment.

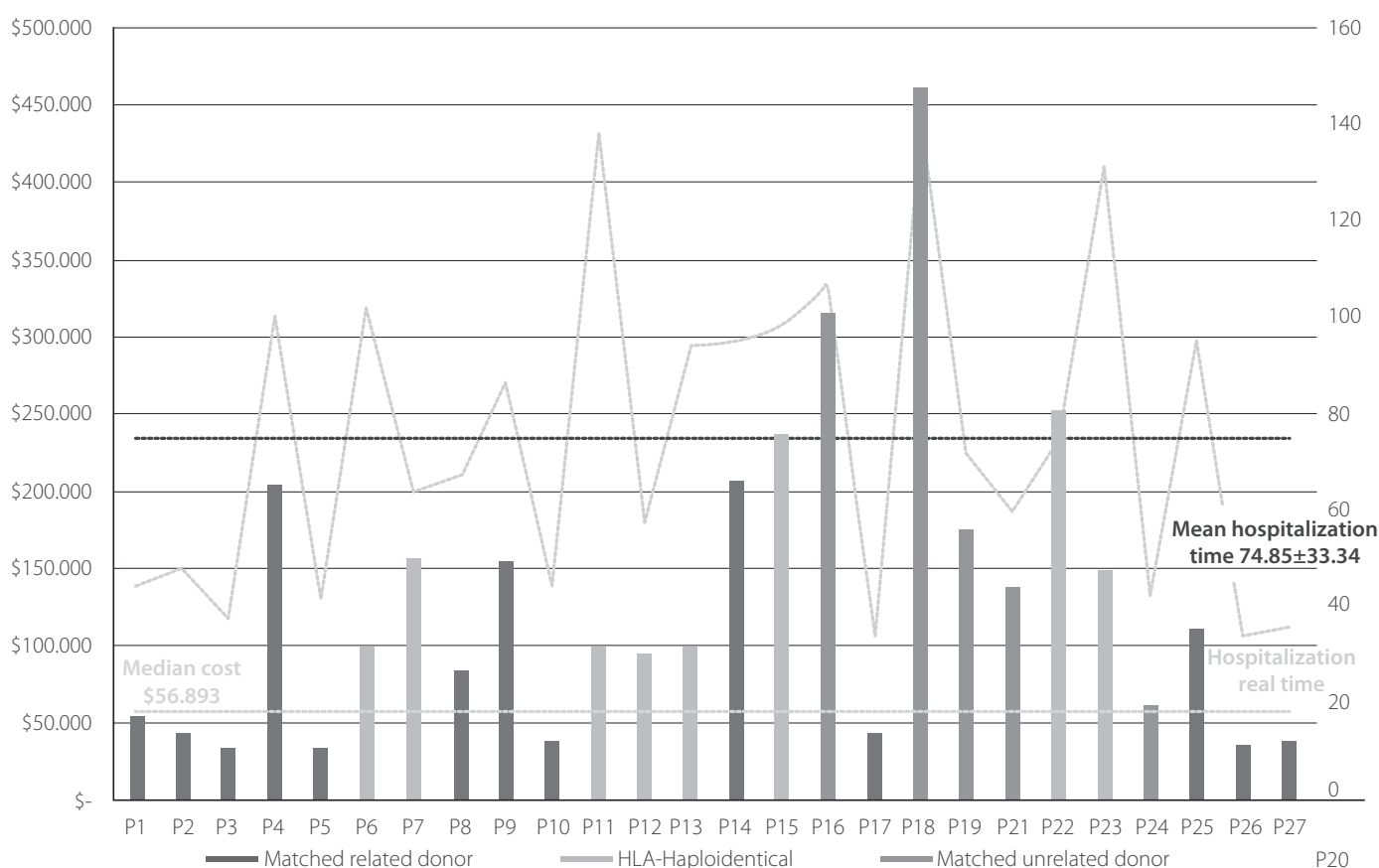

TDABC: time-driven activity-based costing

Figure 2. Admission costs per patient vs. median TDABC cost. 
The aplasia period was the most expensive part of the admission phase, with a median daily cost of 1,431 USD. It should be pointed out that the mean aplasia period was 18 days (11 to 63 days), which partially explains its high median cost that was more than 25,000 USD. The aplasia period incurs high costs due to the required materials, drugs, and hospital structure.

Patients who spent a more extended period on the waiting list for HSCT (>200 days; $\mathrm{n}=13$ ) had higher admission phase cost compared to patients who stayed $<200$ days ( $n=$ 13) $(p=0.047)$. Although the pre-transplant risk score did not seem to be associated with the cost in this sample (data not shown; $\mathrm{p}>0.005$ ), we noticed that patients with higher costs had lower survival rates (Figure 3).

Among our patients, 26.9\% needed antifungals, 38.5\% required antibiotics against multidrug-resistant bacteria, and 53.8\% required antivirals for infection treatment. In addition, drug costs for patients with these types of infections during the admission phase were 40\% higher (P14, P15, P16, P18, P19, and P22). The higher median cost was observed in patients diagnosed with fungal infection (236,765 USD) during the admission phase, probably related to medication cost and prolonged treatment time (minimum six weeks). For patients diagnosed with multidrug-resistant bacteria infection, the median cost was 204,547 USD and for patients with viral infection was 172,252 USD (Table 1). Nutritional therapy (enteral or parenteral) was necessary for $48.2 \%$ of patients, while $29.7 \%$ required mechanical ventilation and $22.2 \%$ dialysis, complications which added costs.

Regarding donors, the median cost of admission for hematopoietic stem cell collection was 2,856 USD (2,481 - 4,004 USD). The variation was mainly related to the graft collection source: bone marrow was more costly than peripheral blood, requiring surgical room, staff, medications, and specific materials.

\section{Post-HSCT costs}

The median cost of the post-HSCT phase was 11,469 USD, but it was a heterogeneous sample. In the post-HSCT phase, 7 patients were followed up. One patient (P17) did not present any complications in the post-HSCT and had a cost of 1,004 USD. Four patients (P21, P25, P26, P27) with mild to moderate complications (readmission for infection or acute graft-versus-host disease) cost between 8,550 to 14,321 USD. The P13 relapsed after HSCT, requiring frequent transfusion support and specific treatment with FLT3 inhibitors, which is a medication of high cost, increasing the price of this phase by 46,407 USD. At last, the most expensive patient of the post-HSCT phase cost analysis (P24) presented multiple infections and severe pulmonary GVHD resistance to first-line treatment, requiring extended intensive care, ending up with a total cost of 597,302 USD.

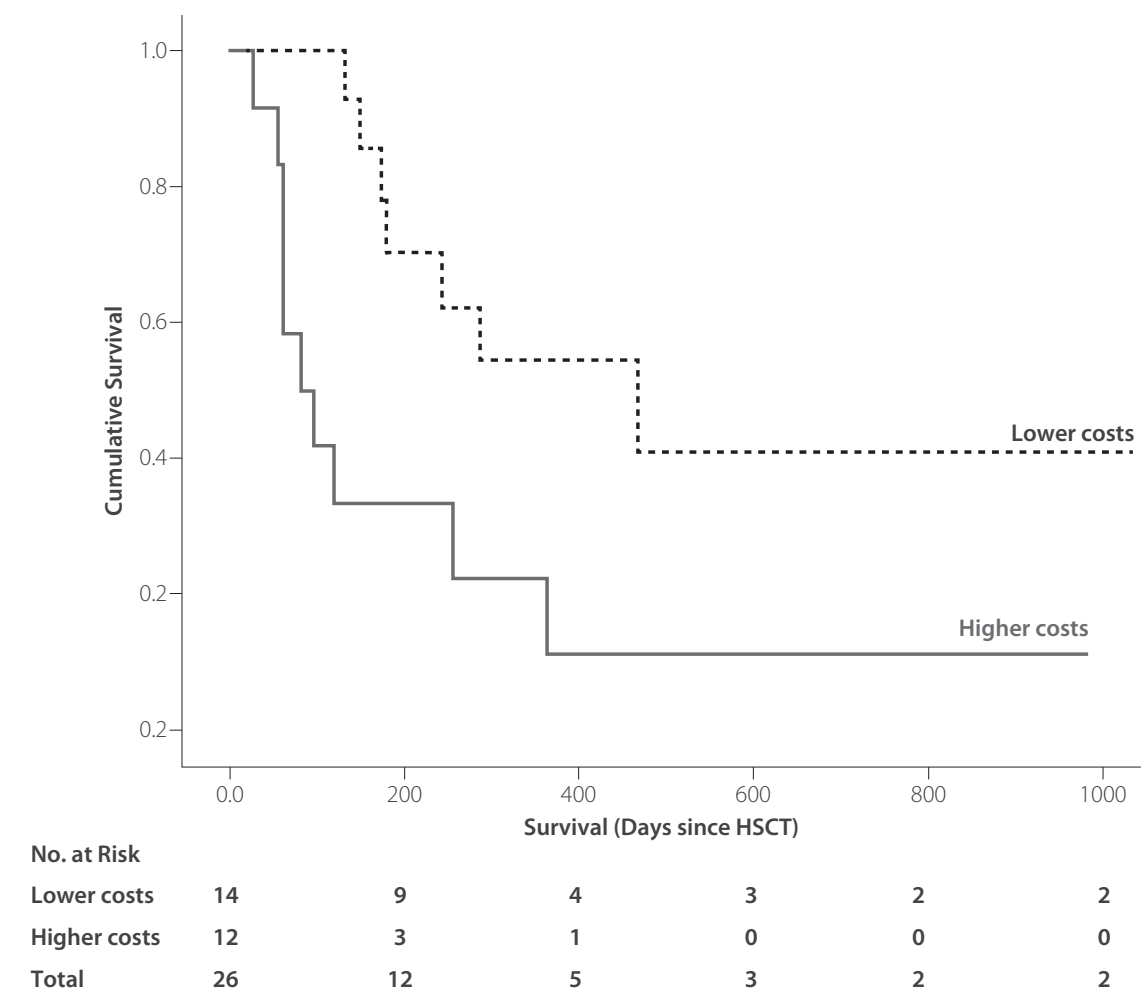

HSCT: hematopoietic stem cell transplantation.

Figure 3. Kaplan-Meier Survival Plot. 
Table 1. Estimated costs for infections during HSCT admission

\begin{tabular}{|c|c|c|c|c|c|c|c|}
\hline ID & HSCT & DRCG & Age (years) & Fungal infection & Viral infection & MRG infection & USD \\
\hline P3 & MRD & $\mathrm{M} / \mathrm{M}$ & 31 & & & & $\$ 34,084$ \\
\hline P5 & MRD & $M / F$ & 33 & & & & $\$ 34,983$ \\
\hline P26 & MRD & $\mathrm{M} / \mathrm{M}$ & 41 & & & & $\$ 36,508$ \\
\hline P10 & MRD & $\mathrm{M} / \mathrm{M}$ & 23 & & Present & & $\$ 37,656$ \\
\hline P27 & MRD & $\mathrm{M} / \mathrm{M}$ & 53 & & & & $\$ 37,927$ \\
\hline P2 & MRD & $M / F$ & 18 & & & Present & $\$ 43,342$ \\
\hline P17 & MRD & $\mathrm{M} / \mathrm{M}$ & 23 & & & & $\$ 43,387$ \\
\hline P1 & MRD & $\mathrm{M} / \mathrm{F}$ & 18 & & & Present & $\$ 54,915$ \\
\hline P24 & MUD & $M / F$ & 30 & & Present & & $\$ 60,280$ \\
\hline P8 & MRD & $\mathrm{F} / \mathrm{F}$ & 45 & & & & $\$ 84,167$ \\
\hline P12 & HAPLO & $\mathrm{F} / \mathrm{F}$ & 25 & & & Present & $\$ 94,450$ \\
\hline P13 & HAPLO & $\mathrm{F} / \mathrm{M}$ & 45 & & Present & & $\$ 99,065$ \\
\hline P6 & HAPLO & $\mathrm{M} / \mathrm{F}$ & 58 & & Present & & $\$ 99,999$ \\
\hline P11 & HAPLO & $\mathrm{F} / \mathrm{M}$ & 39 & & Present & & $\$ 100,050$ \\
\hline P25 & MRD & $\mathrm{M} / \mathrm{M}$ & 11 & Present & Present & & $\$ 110,996$ \\
\hline P21 & MUD & $\mathrm{F} / \mathrm{M}$ & 25 & Present & & & $\$ 137,870$ \\
\hline P23 & MRD & $M / F$ & 4 & & Present & & $\$ 148,303$ \\
\hline P9 & MRD & $F / F$ & 55 & & Present & & $\$ 154,522$ \\
\hline P7 & HAPLO & $M / F$ & 18 & & & & $\$ 156,485$ \\
\hline P19 & MUD & $\mathrm{M} / \mathrm{M}$ & 44 & Present & Present & Present & $\$ 175,385$ \\
\hline P4 & MRD & $F / F$ & 19 & Present & Present & Present & $\$ 204,118$ \\
\hline P14 & MRD & $\mathrm{M} / \mathrm{F}$ & 31 & & Present & Present & $\$ 207,396$ \\
\hline P15 & HAPLO & $\mathrm{M} / \mathrm{M}$ & 34 & & Present & Present & $\$ 236,880$ \\
\hline P22 & HAPLO & $\mathrm{M} / \mathrm{M}$ & 35 & Present & & Present & $\$ 252,107$ \\
\hline P16 & MUD & $\mathrm{F} / \mathrm{M}$ & 25 & Present & Present & Present & $\$ 315,008$ \\
\hline P18 & MUD & $\mathrm{M} / \mathrm{M}$ & 32 & Present & Present & Present & $\$ 461,873$ \\
\hline
\end{tabular}

HSCT: hematopoietic stem cell transplantation; DRGC: donor recipient gender combination; MRD: matched related donor; MUD: matched unrelated donor; HAPLO: Haploidentical donor; MRG: multidrug-resistant germ; M: Male; F: female; Value in US dollars (conversion rate 1 BRL $=0.25$ USD according to the Central Bank of Brazil rates on 12/31/2019).

The costs of the post-HSCT phase are primarily due to staff and input costs (especially medications). There was a need for evaluation/intervention of medical specialties such as dermatology, urology, otolaryngology, general surgery, thoracic surgery, and anesthesiology.

\section{Global HSCT costs and considerations according to transplant type}

When assessing the overall composition of HSCT costs, it is clear that the most significant expense is related to exams and procedures (45\%). The hospital staff cost increased in each phase (7\%; 11\%; 22\%, pre-HSCT, admission, and immediate post-HSCT, respectively). The hospital's physical structure, on the other hand, has the most negligible impact on the final overall cost (12\%) and was most relevant in the admission phase (30\%). Table 2 shows the total cost estimates for each HSCT phase according to transplant type.
The patient global cost estimate considering the sum of median in the pre-transplant, transplant, and post-transplant phases was 69,104 USD, with all costs involved such as drugs, materials, human resources, multidisciplinary team care activities - including physician's fees, and physical structure. It was observed that the total cost for each type of transplant was heterogeneous. The total cost of MUD HSCT seemed higher than both MRD and HLA-haploidentical donor HSCT (Table 2).

\section{Discussion}

This study presented data on the micro-costing of allogeneic HSCT in Brazil using the TDABC method, describing the main costs in each phase of the transplantation. In the pre-HSCT phase, the median cost was 742 USD (IQR 25,75: 429 - 1,497 USD), the highest cost being related to medical exams and dental procedures (23\%). The median cost of the admission 
Vargas DF, David CN, Horvath JDC, Silva TS, Pereira MP, Rigoni LDC, Sartor ITS, Zavaglia GO, Kern LB, Luft TD, Tolves FL, Scherer FF, Pereira JC, Barrionuevo F, Etges APBS, Zanotto BS, Daudt LE, Cruz LN, Polanczyk CA, Astigarraga CC

Table 2. Median global costs and for each HSCT phase according to the transplant type

\begin{tabular}{ccccc}
\hline & & Patient & & \\
\hline HSCT type & Pre-HSCT & Admission & Post-HSCT & Total* \\
\hline MRD & 1,193 & 43,387 & 10,010 & 54,590 \\
\hline HAPLO & 653 & 124,177 & 46,407 & 171,236 \\
\hline MUD & 690 & 479,885 & 303,810 & 479,885 \\
\hline
\end{tabular}

HSCT: hematopoietic stem cell transplantation. MRD = matched related donor; MUD: matched unrelated donor; HAPLO= Haploidentical donor; ${ }^{*}$ Total value in US dollars (conversion rate $1 \mathrm{BRL}=0.25$ USD according to the Central Bank of Brazil rates on 12/31/2019).

phase was 56,893 USD (IQR 25,75: 32,165 - 193,714 USD), in which the aplasia period was the most expensive, with a median daily cost of 1,431 USD. In the post-HSCT phase, the cost ranged from 1,004 to 597,302 USD, in which 5 of 7 patients required readmission for infection or acute graft-versus-host disease. The median global cost varied among the MRD, Haplo and MUD (54,590 vs. 171,236 vs. 479,885 USD, respectively). The patient's estimated global cost was 69,104 USD.

The cost of HSCT, regardless of type, is high and heterogeneous, varying according to risk factors and needs of highly complex medical procedures for each individual (Karabatsou et al., 2016). Costs of transplantation will vary depending on each region or country's health management policies and models, causing variations in how the price is analyzed in micro-costing studies and values that are not fully comparable between centers (Debals-Gonthier et al., 2018; Rivera-Franco et al., 2017).

In Brazil, the Unified Health System reimburses public transplantation centers through a funding package for each HSCT performed (Brazil, 2012). Another reimbursement value table is used for allogeneic transplant procedures, such as total body irradiation (TBI) and post-transplant complications. Daily ICU is an exception and is not foreseen during the postHSCT phase, which is not reimbursed by the health system. In addition to the heterogeneity of patient costs, these factors show the complexity of establishing a single collection package.

Regarding the characteristics of HSCT, it has been described that the mean cost may depend on the patient's procedure-related mortality risk, with reported mean costs for high, intermediate, and low-risk groups of 281,000 USD, 73,300 USD, and 54,400 USD, respectively (Kerbauy et al., 2012). Although we didn't find a significant association between cost and risk score, we speculate that our high cost can be related to the mortality risk of our population since most patients were intermediate and high risk by EBMT and PAM score. Besides that, our high cost is due to our longer hospitalization stay (74.85 \pm 33.34 days) than to the mean time of 30 days reported in other studies (AHRQ, 2011; Rivera-Franco, 2017), which can reach 40 days for patients $>55$ years old (Debals-Gonthier, 2018).

Other studies from the same public institution where our patients came from also reported long hospitalization time and long time between diagnosis and HSCT (>12 months) for patients with low socioeconomic status (Paz et al., 2018; Pitombeira et al., 2013; Silla et al., 2009). Since the limitation in the number of hospital beds for performing HSCT in Brazil, patients with indications for transplantation and with a donor located remain on a waiting list until bed availability (Rodrigues et al., 2020). Besides the order of arrival, this list considers prioritization criteria such as age and disease type (Brazil, 2017). In this study, there was a significant increase in the cost of admission phase for patients who remained $>200$ days on the waiting list. In addition to the high cost of such a complex treatment as the allogeneic HSCT, maintenance and support treatment of the patient waiting for the HSCT adds costs to the health system, reinforcing the importance of investing in structure focused on HSCT with proper capacity.

Regarding the type of transplant, MRD HSCT seemed to cost less than MUD HSCT in this sample. MRD and HLA-haploidentical HSCT cost 3.5 and 2.2 times less than MUD HSCT, respectively. MUD HSCT also involves costs of searching for a donor in the Brazilian Bone Marrow Donor Registry (REDOME) and the National Marrow Donor Program (Rivera-Franco et al., 2017) when an international donor is indicated, all of which is covered by the Brazilian Unified Health System. The greater complexity and complication risks (especially infections) involved in MUD HSCT are reflected in its high cost. Since it also has higher mortality and shorter survival time (Debals-Gonthier et al., 2018), MUD HSCT is the last therapeutic alternative among transplant-type options.

Our study demonstrated that the cost composition for each phase of HSCT treatment differs due to the specific procedures involved. Medications are one of the main components of the total cost, especially in patients that needed infection treatment drugs. Generally, patients diagnosed with fungal infection due to prolonged neutropenia will also present viral and multidrug-resistant bacterial infections during admission, increasing the costs, as was shown in our sample. Considering that we observed that infectious processes can increase the cost of treatment, therapeutic strategies evaluated, such as prophylaxis with certain drugs in specific scenarios, can reduce the total cost of transplantation. However, cost-effectiveness studies are not available for all types of drugs used in HSCT. 
We sought to carry out a detailed and accurate cost assessment to support our results and present a reliable estimate of HSCT cost in our region. However, this study has some limitations, especially regarding the sample size and data collection from a single center. It should also be mentioned that a complete economic evaluation could not be carried out since we did not perform a cost-effectiveness assessment. In Brazil, immunosuppressant drugs used in the post-HSCT phase are regulated by the health department, and the state government makes their payment; thus, it was not possible to include their cost in this study. Although we removed the hospital's profit margin from the costs presented in this paper for more accurate results, caution should be used when extrapolating these results to other centers.

Health economic studies are still uncommon. In other countries, substantial inconsistencies in costing methods and reporting standards have been described in financial analyses, resulting in low acceptance and a lack of interest in economic evaluation (Clarke-Deelder et al., 2019).

Future studies to explore these results to design reimbursement strategies considering the real-world cost evidence (e.g., transport, temporary housing close to the transplant center, loss of production, etc.) may assess alternatives based on the care-pathway phase, outcomes, and the risk score. While strategies that contribute to accelerating the waiting time in the list for a transplant, it may include in its effectiveness analyses the cost-saving opportunity associated with anticipating the transplant. The cost information with the granularity level presented on this research is essential for those scientific and health policy advances. Our results can be used to subside economic evaluation studies, adding value to guide decision-making actions of health resources management.

\section{Conclusion}

The cost of HSCT is high and variable for a sample of patients undergoing HSCT at an institution in southern Brazil. MUD HSCT was 3.5 and 2.2 times more costly than MRD and HLA-haploidentical HSCT, respectively. The cost variability was identified in all the care pathway phases, affirming that it is affected by patients' length of time spent on the waiting list, length of hospitalization stay, and infection identification.

\section{Acknowledgments}

The study staff would like to thank the General Coordination Office of the Brazilian National Transplant System (CGSNT-MS) staff; the Department of Specialized and Thematic Care; the Specialized Health Care Office; and the Brazilian Ministry of Health.

\section{References}

Agency for healthcare research and quality (AHRQ). Healthcare cost and utilization project (HCUP) - community-level statistcs. Disponível em: <http://www.ahrq.gov/data/hcup/index.html>. Acesso em: 25 jun. 2021

Ashfaq K, Yahaya I, Hyde C, Andronis L, Barton P, Bayliss S, et al. Clinical effectiveness and cost-effectiveness of stem cell transplantation in the management of acute leukaemia: a systematic review. Health Technol Assess. 2010;14(54):iii-iv, ix-xi, 1-141.

Au BK, Gooley TA, Armand P, Fang M, Madtes DK, Sorror ML, et al. Reevaluation of the pretransplant assessment of mortality score after allogeneic hematopoietic transplantation. Biol Blood Marrow Transplant. 2015;21(5):848-54.

Brasil. Lei no 8.080. Dispõe sobre as condições para a promoção, proteção e recuperação da saúde. 2017.

Brasil. Ministério da Saúde. Portaria de consolidação nº 4. Consolidação das normas sobre os sistemas e os subsistemas do Sistema Único de Saúde. 2017.

Brasil. Portaria no 845. estabelece estratégia de qualificação e ampliação do acesso aos transplante. 2012.

Clarke-Deelder E, Vassall A, Menzies NA. Estimators used in multisite healthcare costing studies in low- and middle-income countries: a systematic review and simulation study. Value Health. 2019;22(10):1146-53.

de Melo Rodrigues AL, Bonfim C, Seber A, Colturato VAR, Zecchin VG, Nichele S, Daudt LE, Fernandes JF, Vieira AK, Darrigo Junior LG, Gomes AA, Arcuri L, Lenzi L, Picharski GL, Ribeiro RC, de Figueiredo BC. Allogeneic Hematopoietic Stem Cell Transplantation for Children and Adolescents with Acute Myeloid Leukemia in Brazil: A Multicentric Retrospective Study. Cell Transplant. 2020;29:963689720949175.

Debals-Gonthier M, Siani C, Faucher C, Touzani R, Lemarié-Basset C, Chabannon C, Furst S, Devillier R, Harbi S, Castagna L, Caymaris L, Blaise D, Le Corroller Soriano AG. Cost-effectiveness analysis of haploidentical vs matched unrelated allogeneic hematopoietic stem cells transplantation in patients older than 55 years. Bone Marrow Transplant. 2018;53(9):1096104.

Donovan CJ, Hopkins M, Kimmel BM, Koberna S, Montie CA. How Cleveland Clinic used TDABC to improve value. Healthc Financ Manage. 2014;68(6):84-8.

da Silva Etges APB, Cruz LN, Notti RK, Neyeloff JL, Schlatter RP, Astigarraga CC, et al. An 8-step framework for implementing time-driven activity-based costing in healthcare studies. Eur J Health Econ. 2019;20(8):1133-45.

Etges APBDS, Ruschel KB, Polanczyk CA, Urman RD. Advances in Value-Based Healthcare by the Application of Time-Driven Activity-Based Costing for Inpatient Management: A Systematic Review. Value Health. 2020;23(6):812-23.

Gratwohl A, Stern M, Brand R, Apperley J, Baldomero H, de Witte T, et al.; European Group for Blood and Marrow Transplantation and the European Leukemia Net. Risk score for outcome after allogeneic hematopoietic stem cell transplantation: a retrospective analysis. Cancer. 2009;115(20):4715-26.

Gratwohl A. The EBMT risk score. Bone Marrow Transplant. 2012;47(6):749-56.

Jaime-Pérez JC, Heredia-Salazar AC, Cantú-Rodríguez OG, Gutiérrez-Aguirre H, Villarreal-Villarreal CD, Mancías-Guerra C, et al. Cost structure and clinical outcome of a stem cell transplantation program in a developing country: the experience in northeast Mexico. Oncologist. 2015;20(4):386-92.

Kaplan RS, Anderson SR. Time-driven activity-based costing. Harv Bus Rev. 2004;82(11):131-8, 150. 
Vargas DF, David CN, Horvath JDC, Silva TS, Pereira MP, Rigoni LDC, Sartor ITS, Zavaglia GO, Kern LB, Luft TD, Tolves FL, Scherer FF, Pereira JC, Barrionuevo F, Etges APBS, Zanotto BS, Daudt LE, Cruz LN, Polanczyk CA, Astigarraga CC

Kaplan RS, Porter ME. The big idea: how to solve the cost crisis in health care. 2011. Available from: <https://hbr.org/2011/09/how-to-solve-the-cost-crisis-in-health-care>. Access on: May 4, 2021.

Karabatsou D, Tsironi M, Tsigou E, Boutzouka E, Katsoulas T, Baltopoulos G. Variable cost of ICU care, a micro-costing analysis. Intensive Crit Care Nurs. 2016;35:66-73.

Keel G, Savage C, Rafiq M, Mazzocato P. Time-driven activity-based costing in health care: A systematic review of the literature. Health Policy. 2017;121(7):755-763.

Kerbauy FR, Morelli LR, de Andrade CT, Lisboa LF, Cendoroglo Neto M, Hamerschlak N. Predicting mortality and cost of hematopoietic stem-cell transplantation. Einstein (Sao Paulo). 2012;10(1):82-5.

Razgallah Khrouf M, Achour L, Thabti A, Soussi MA, Abdejelil N, Lazreg O, et al. Direct cost analysis of the second year post-allogeneic hematopoietic stem cell transplantation in the Bone Marrow Transplant Centre of Tunisia. J Mark Access Health Policy. 2017;5(1):1335161.

Leelahavarong P, Chaikledkaew U, Hongeng S, Kasemsup V, Lubell Y, Teerawattananon $Y$. A cost-utility and budget impact analysis of allogeneic hematopoietic stem cell transplantation for severe thalassemic patients in Thailand. BMC Health Serv Res. 2010;10:209.

Nunes LN, Klück MM, Fachel JMG. Comparação de métodos de imputação única e múltipla usando como exemplo um modelo de risco para mortalidade cirúrgica. Rev Bras Epidemiol. 2010;13:596-606.

Paz A, Rigoni L, Fischer G, Schittler M, Pezzi A, Valim V, et al. Donor characteristics and hematopoietic stem cell transplantation outcome: experience of a single center in Southern Brazil. Hematol Transfus Cell Ther. 2018;40(2):136-42.

Pitombeira BS, Paz A, Pezzi A, Amorin B, Valim V, Laureano A, et al. Validation of the EBMT Risk Score for South Brazilian Patients Submitted to Allogeneic Hematopoietic Stem Cell Transplantation. Bone Marrow Res. 2013;2013:565824.

Porter ME. What is value in health care? N Engl J Med. 2010;363(26):2477-81.

Porter ME, Lee TH. The strategy that will fix health care. Harvard business review. 2013. Available from: https://hbr.org/2013/10/the-strategy-that-will-fix-health-care.

Preussler JM, Denzen EM, Majhail NS. Costs and cost-effectiveness of hematopoietic cell transplantation. Biol Blood Marrow Transplant. 2012;18(11):1620-8.

Rivera-Franco MM, Leon-Rodriguez E, Castro-Saldaña HL. Costs of hematopoietic stem cell transplantation in a developing country. Int J Hematol. 2017;106(4):573-80.

Silla L, Fischer GB, Paz A, Daudt LE, Mitto I, Katz B, et al. Patient socioeconomic status as a prognostic factor for allo-SCT. Bone Marrow Transplant. 2009:43(7):571-7.

Wingard JR, Majhail NS, Brazauskas R, Wang Z, Sobocinski KA, Jacobsohn D, et al. Long-term survival and late deaths after allogeneic hematopoietic cell transplantation. J Clin Oncol. 2011;29(16):2230-9.

Xu X, Grossetta Nardini HK, Ruger JP. Micro-costing studies in the health and medical literature: protocol for a systematic review. Syst Rev. 2014 May 21;3:47. 